\title{
DEPARTAMENTO DE MICOLOGIA
}

\section{P0236 Paracoccidoidomicose disseminada e grave. Recuperação com auxílio de nutrição parenteral}

\author{
Autores: $\quad$ Marques SA, Lastória JC, Reis IRT, Ferreira AGT, Marques MEA. \\ INSTITUIÇÃo: Faculdade de Medicina de Botucatu - Unesp, SP
}

\begin{abstract}
INTRODuÇão: Paracoccidioidomicose (PbMicose), na sua Forma Aguda - Subaguda (Tipo Juvenil), caracterizase por acometer pacientes mais jovens e apresentar tropismo pelo Sistema Retículo-Endotelial do hospedeiro. Os maiores índices de letalidade causados pela PbMicose encontram-se nesta forma clínica, dado a tendência à disseminação da doença. ara diversos órgão e sistemas, incluindo o tubo digestivo.

Relato de Caso: Paciente de 33 anos, masculino, ex-lavrador, que referia há 2 anos lesões na face, de evolução lenta, mas que há 2 meses assumiram caráter rapidamente progressivo, com múltiplas lesões, que ulceravam, tomando quase toda a mesma. Acompanhada por queda do estado geral, febre e emagrecimento de 9 quilos no período. À internação, além do descrito, apresentava adenomegalia generalizadas, hepatoesplenomegalia e distensão abdominal. Submetido à investigação diagnóstica, confirmou-se PbMicose, iniciandose terapêutica com Anfotericina B (Anf.B). Investigações relativas à infecção pelo HIV, HBV e HCV foram negativas. Em pou cos dias desenvolveu pancreatite aguda hemorrágica e edematosa e síndrome da resposta inflamatória sistêmica, com ascite e derrame pulmonar com velamento completo do hemitoráx E. Nesta oportunidade a tomografia computadorizada do abdômen mostrou hepatoesplenomegalia com múltiplos nódulos parenquimatosos, adenomegalia hilar hepática, periaórtica e pericavas e ascite. Evoluiu com piora acentuada do estado geral. Introduzido sistema de nutrição parenteral isolada inicialmente e posteriormente nutrição parenteral e enteral, múltiplas transfusões, manutenção da Anf. B, 1,0 mg/kg/dia e medidas de suporte geral. Evoluiu com recuperação progressiva após dois meses de internação, com cicatrização das lesões e melhora do estado geral, porém mantendo ascite hemorrágica. Submetido a videolaparoscopia intra-peritonial, observou-se a manutenção de ascite hemorrágica com pontos de sufusão hemorrágica múltiplos no peritônio com hipóteses de PbMicose peritonial diferencial com Tuberculose de peritônio. No momento recuperação clínica de $80 \%$ e aguardando a definição diagnóstica do quadro peritonial.

Dıscussão: Paracoccidioidomicose tipo juvenil grave, era mais observada no passado, quando os pacientes apresentavam-se para tratamento ou eram diagnosticados mais tardiamente, apresenta potencial de morbidade e letalidade altos. 0 presente relato apresenta caso incomum pela expressão clínica exuberante e gravidade, evoluindo com sucesso pelo esforço assistencial multidisciplinar.
\end{abstract}

Motivo dA APRESEnTAÇ̃̃o: Salientar o papel da Dermatologia no diagnóstico precoce dos casos semelhantes e salientar o papel decisivo de terapêuticas agressivas e do suporte nutricional parenteral auxiliar.

\section{P0237 Aspergilose cutânea: relato de caso}
AUTORES:
Wu SLC, Negro SPC, Juang JM, Oliveira CB, Michalany NS.
INSTITUIÇÃO:
Hospital do Servidor Público Municipal de São Paulo, SP.

INTRODuÇÃo: A aspergilose é infecção fúngica oportunística muito freqüente em imunossuprimidos. A espécie mais comum é o Aspergillus furmigatus e as condições predisponentes são doenças malignas hematológicas, imunossupressão terapêutica para transplantes e como efeito colateral de terapias antineoplásicas para tumores sólidos, corticoterapia prolongada, neutropenia e disfunções neutrofílicas.

Relato do CASo: M.S.O., 66 anos, viúva, do lar, brasileira, branca. Queixa de ter notado há 15 dias da internação o aparecimento de "ferida no nariz". Ao exame dermatológico apresentava placa infiltrada eritematosa com necrose na região nasal e penetrando as coanas bilateralmente, além de lesões exsulceradas com secreção esbranquiçada no palato e na comissura labial à direita. Realizada biópsia e exame anátomopatológico compatível com aspergilose. Antecedentes pessoais de mieloma múltiplo em programação quimioterápica, tendo sido submetida a pulso há 1 mês. A doente foi internada e durante a internação recebeu terapêutica com anfotericina $B$, porém ocorreu deterioração da função renal e a medicação foi suspensa. Houve então piora do quadro clínico evoluindo para êxito letal após 15 dias da internação.

Dıscussão: De acordo com o apresentado na literatura, aspergilose cutânea é doença rara, apresentando- 
se como placas eritematosas únicas ou múltiplas ou maculo-pápulas que simulam exantema por drogas e que podem pustulizar e evoluir para necrose. Nas lesões cutâneas, pode ser encontrado o Aspergillus pelo exame micológico direto com potassa. Raramente é fatal por sua condição, porém por vir associada à condições de imunodepressão pode freqüentemente evoluir para êxito letal, como descrito no caso, em que observamos a associação da manifestação das lesões com a condição de imunossupressão da doente (portadora de mieloma múltiplo e granulocitopênica).

MOTIVO DA APRESENTAÇÃO: Raridade do caso.

\title{
P0238 Dermatofitose com acometimento de uma mão e dois pés (two-feet-one-hand syndrome)
}

\author{
Autores: $\quad$ Cunha Jr. PAM, Aguiar AL, Cunha JL, Martins CJ, Ferreira JA. \\ InSTITUIÇÃo: Hospital Universitário Gaffrèe e Guinle - UNIRIO - Rio de Janeiro, RJ
}

INTRODUÇÃo: As infeç̧ões por fungos do tipo Uma Mão e Dois Pés não são incomuns. Acometem freqüentemente homens adultos, da quarta à sexta década de vida. $O$ desenvolvimento da tinea pedis e da onicomicose geralmente precede 0 aparecimento da tinea manum.

Relato de Caso: Paciente, masculino, 32 anos, branco, referia lesões descamativas nas regiões plantares e na região palmar direita com evolução de um ano. 0 exame dermatológico mostrou lesões descamativas e hiperceratóticas na região palmar direita e plantar bilateralmente, além de onicólise e distrofia das unhas do segundo e quarto quirodáctilos direitos. Realizado exame micológico de todas as regiões acometidas, que evidenciou hifas septadas e ramificadas de um provável dermatófito. A cultura em meio de Mycosel demonstrou crescimento de colônias características de Trichophyton rubrum. 0 diagnóstico conclusivo foi de dermatofitose acometendo uma mão e os pés. 0 tratamento instituído foi a pulsoterapia com itraconazol, durante quatro meses, levando à regressão total das lesões.

Dıscussão: Mesmo sendo uma manifestação de dermatofitose não incomum, o diagnóstico clínico pode ser difícil por apresentar diagnósticos diferenciais, como psoríase, ptiríase rubra pilar, eczema, entre outros. Dessa forma torna-se imprescindível o exame micológico de todas as áreas afetadas para confirmação diagnóstica.

Motivo DA APRESENTAÇÃo: Demonstração clínica de uma dermatofitose de aspecto peculiar pouco diagnosticada.

\section{P0239 Paracococcidioidomicose sarcoídica: uma apresentação rara}

\author{
Autores: $\quad$ Streck AP, Gonçalves RV, Coutinho ZP, Monteiro CS, Martins CJ. \\ InSTITUIÇÃo: Hospital Universitário Gaffrèe e Guinle - UNIRIO - Rio de Janeiro, RJ
}

INTRODuçÃo: A Paracoccidioidomicose ou Blastomicose Sul-Americana é uma doença sistêmica granulomatosa de evolução aguda, subaguda ou crônica causada por fungo dimorfo Paracoccidioides brasiliensis (Pb). A primeira descrição é de Adolpho Lutz em 1908 e é uma das mais prevalentes micoses da América Latina. A transmissão ocorre principalmente por via inalatória, embora raramente possa ocorrer a inoculação cutâneomucosa direta. Entre as suas formas clínicas é descrita a variante sarcoídica, rara, que representaria forma hiperérgica da doença, que deve ser diferenciada de outras doenças granulomatosas.

ReATO dE CAso: Paciente de 67 anos, feminino, branca, natural e procedente de Valença, RJ (zona rural); com aparecimento de lesão eritematosa, plana, na região retroauricular esquerda assintomática, com posterior acometimento da hemiface ipsilateral e tornando-se progressivamente papulosa e infiltrada associada a madarose parcial bilateral, sendo tratada como Hanseníase Paucibacilar, sem melhora. Procurou então o serviço com mesmo quadro clínico. Ao exame ausência de lesões na cavidade bucal, linfonodomegalias ou sinais de emagrecimento. Foi realizada biópsia que demonstrou processo inflamatório granulomatoso em meio ao qual se observam numerosas estruturas fúngicas características de P. braziliensis. Exames gerais e Rx-tórax foram normais. Sorologia: Imunodifusão dupla para P. brasilien sis= negativa. Foi tratada com Sulfametoxazol + Trimetoprim via oral, com melhora acentuada das lesões.

Dıscussão: A Paracoccidioidomicose na forma sistêmica pode acometer vários órgãos, com predileção por mucosas, pele, linfonodos, pulmões, glândulas supra-renais e sistema nervoso. Na pele, caracteriza-se por lesões polimorfas, em vários estágios evolutivos, de acordo com o local de inoculação e o estado imunológico do indivíduo, variando em apresentação desde lesões pápulo-eritematosas, pápulo-pustulosas, pápulo-vege- 
tantes até úlcero-crostosas. É também descrita a forma sarcoídica, mais rara, com predominância em homens entre 30 a 50 anos, apresentando-se como pápulas ou placas eritêmato-acastanhadas ou violáceas, de limites precisos, requerendo o diagnóstico diferencial com Hanseníase Tuberculóide, Sarcoidose e Lúpus Eritematoso. Motivo dA ApRESEnTAÇão: Demonstrar uma manifestação cutânea rara da Paracoccidiodomicose.

\title{
P0240 Cromomicose disseminada associada a carcinoma verrucoso
}

\author{
Autores: $\quad$ Castro ACM, Lima VGF, Rodrigues AN, Santos AJC, Borges CB, Silvestre CS. \\ INSTITUIÇÃo: Serviço de Dermatologia do Hospital das Clínicas - Universidade Federal de Goiás - Goiânia, GO
}

\begin{abstract}
INIRODução: A cromomicose é uma infecção fúngica crônica de pele e tecido subcutâneo causada por fungos demáceos como Fonsecaea pedrosoi, Phialophora verrucosa, F. compactum e Cladosporium carrionii. Os fungos encontram-se no solo ou em vegetais e são inoculados por trauma ou ferimentos. Acomete principalmente homens trabal hadores rurais em idade adulta. Geralmente, localiza-se em membros inferiores, de forma unilateral.

Relato DE CASO: Paciente de 64 anos, sexo feminino, natural e procedente de Petrolina, GO, com história de lesão verrucosa em perna direita com crescimento lento de aproximadamente 30 anos, que nos últimos 8 anos havia espal hado mais rapidamente para outras áreas do corpo. No dorso de mão esquerda havia lesão exuberante e dolorosa. Ao exame dermatológico: placas verrucosas, acrômicas e descamativas, disseminadas em membros superiores e inferiores, e lesão vegetante em dorso mão esquerda, $8 \times 6 \mathrm{~cm}$, com flexão fixa de $3^{\circ}, 4^{\circ}$ e $5^{\circ}$ quirodáctilos, com a mão em garra, e onicogrifose. Diagnóstico clínico-patológico em 1997 de cromomicose, sem adequado acompanhamento. Realizadas novas biópsias e cultura das lesões dos braços e pernas, e exérese de lesão em dorso de mão com cauterização por um cirurgião. As biópsias e cultura foram compatíveis com cromomicose por Fonsecaea pedrosoi, porém o cirurgião não havia encaminhado material para anatomopatológico. Iniciado tratamento com Itraconazol $200 \mathrm{mg} / \mathrm{dia}$. Após 40 dias a paciente retornou apresentando recidiva da lesão vegetante em dorso mão esquerda, agora com $5 \times 4 \mathrm{~cm}$. Procedeu-se à exérese da lesão e encaminhada para histopatológico, que veio compatível com carcinoma verrucoso.

Dıscussão: Em nosso meio observamos com muita freqüência casos de cromomicose, sendo o agente mais comum Fonsecaea pedrosoi. Porém casos como este disseminado são raros. É descrita associação entre carcinoma espinocelular e cromomicose, geralmente moderadamente diferenciados. 0 carcinoma verrucoso, tipo bem diferenciado de carcinoma espinocelular, é mais relatado em pés, região genital e mucosa oral, associados a infecção pelo vírus HPV. A associação entre carcinoma verrucoso e cromomicose, além de ser pouco freqüente, torna-se mais relevante pela semelhança entre $o$ aspecto vegetante que ambas podem assumir. Sendo assim é sempre muito importante a realização de anatomopatológico para diferenciá-las.
\end{abstract}

Motivo dA APRESENTAÇão: Relatar caso de cromomicose disseminado associado a carcinoma verrucoso, e reafirmar a importância do anatomopatológico em todas lesões retiradas.

\section{P0241 Rinosporidiose nasal: relato de dois casos}

\author{
Autores: $\quad$ Silva RR, Corrêa TD, Figueiredo ET, Souza MTVL, Feitosa MSC. \\ INSTITUIÇÃo: UFMA-LIDER - São Luís, MA
}

\begin{abstract}
INTRODuÇão: A Rinosporidiose é uma doença crônica infecciosa causada por fungo. Seu agente etiológico é o Rhinosporidium seeberi, patógeno oportunista, não invasivo que provavelmente requer uma lesão para a entrada no organismo. Esta infecção acomete a membrana da mucosa nasal e conjuntiva ocular de humanos e animais, produzindo lentamente crescentes massas que se transformam em pólipos. Os sintomas dependem do estágio de desenvolvimento do tumor e do local afetado. Com este trabal ho relatamos os casos diagnosticados no Instituto Maranhense de Oncologia Aldenora Bello (IMOAB) no ano de 2005, discutindo as principais características clínicas, etiologia, patogênese, diagnóstico e terapêutica.

Relato de Casos: Caso 1: J.S.S., masculino, 17 anos, natural e residente em Caxias, MA, estudante, ensino fundamental incompleto. Procurou o IMOAB apresentando epistaxe pela narina direita. Ao exame clínico, notouse lesão polipóide de narina direita, sendo feita ressecção cirúrgica. À macroscopia, observou-se fragmento tecidual irregular medindo $2,5 \mathrm{~cm} \times 2 \mathrm{~cm}$, rugoso, brancacento. Aos cortes, tecido firme e elástico. 0 diagnóstico anatomopatológico foi de Rinosporidiose nasal. Caso 2: J.R.M.M., masculino, 17 anos, natural e residente em Penalva, MA, estudante, ensino fundamental incompleto. Procurou o IMOAB apresentando tumoração
\end{abstract}


em fossa nasal direita acompanhada de sinais flogísticos locais. Ao exame clínico, evidenciou-se lesão polipóide em fossa nasal direita, sendo feita extirpação cirúrgica. 0 exame histopatológico mostrou três fragmentos teciduais irregulares, rugosos, pardacentos e elásticos, com diagnóstico de Rinosporidiose nasal.

Dıscussão: Os mecanismos de infecção do Rhi nosporidium seeberi não são bem conhecidos, mas o contágio parece ser exógeno por meio da poeira e da água. Uma vez na mucosa, o esporo penetra o epitélio e desencadeia o processo inflamatório. No nariz, produz obstrução lenta e progressiva com sensação de corpo estranho, rinorréia, odor fétido, com presença de esporos, epistaxe, massa vegetante, múltipla ou única, séssil ou pediculada, avermelhada, friável e sangrante. 0 diagnóstico é sugerido pela anamnese e confirmado pela presença de esporos na secreção nasal e pelo exame histopatológico. Nos casos relatados, observa-se uma história de provável exposição por meio de banhos em rios. 0 tratamento ideal é a excisão com alça fria seguida de diatermo-coagulação na base de implantação. O prognóstico é bom quando a excisão for total.

MotIVO DA APRESENTAÇÃO: A rinosporidiose é uma doença rara, porém os autores evidenciaram dois casos típicos em curto espaço de tempo. Os autores chamam atenção para o diagnóstico diferencial da rinosporidiose entre as diversas lesões polipóides do nariz, inclusive lesões malignas.

\title{
P0242 Esporotricose ocular - Forma rara de apresentação da doença
}

\author{
AUTORES: $\quad$ Sampaio AA, Guedes LS, Biancardi AL, Barreto RPP, Rodrigues MPM. \\ InstituIção: Hospital Universitário Clementino Fraga Filho, Universidade Federal do Rio de Janeiro - \\ Rio de Janeiro, RJ
}

\begin{abstract}
INTRODUÇÃO: Esporoticose é uma doença causada pelo fungo dimorfo Sporothrix schenckii, afetando homens e animais. Ela atinge a pele e o tecido subcutâneo e, mais raramente, mucosas e órgãos internos. A inoculação no homem se dá de forma direta, por meio de traumatismos na pele ou mucosas, como arranhaduras por animais, em que se destacam os gatos como principais vetores. Descrevemos um caso de Esporotricose Ocular na forma mucosa localizada, manifestando-se como Síndrome Oculoglandular de Parinaud, que se caracteriza por conjuntivite granulomatosa unilateral e linfadenopatia regional ipsilateral. Serão discutidos os aspectos epidemiológicos, clínicos, métodos diagnósticos e terapêuticos desta rara doença.

Relato do Caso: I.C.S., 44 anos, com queixa de hiperemia ocular à esquerda e linfadenopatia pré-auricular ipsilateral. Informa ter cinco gatos em seu domicílio, dois deles em tratamento para Esporotricose. Relatou sofrer arranhaduras e mordeduras de gatos com freqüência. Evoluiu com surgimento de pequeno granuloma da conjuntiva tarsal inferior, onde foi realizada biópsia para análise histopatológica e exame micológico. A cultura do material foi positiva paraS. schenckii. Foi então instituída terapia com Itraconazol 100 mg/dia por 60 dias, com resposta satisfatória.
\end{abstract}

Dıscussão: Relatamos um caso de uma paciente que apresentou contato com gatos infectados pelo S. schenc kii, tendo como prováveis sítios de inoculação deste parasita as lesões provocadas pelos felinos. A forma clínica de Esporotricose desenvolvida por esta paciente é rara, pouco descrita na literatura. A Esporotricose, antes considerada doença do meio rural, vem sendo observada cada vez mais em grandes centros urbanos. A sua incidência em nosso meio vem crescendo nos últimos dez anos, devido a uma epidemia em felinos. 0 motivo desta epidemia ainda não foi esclarecido.

Motivo DA APRESENTAÇão: Forma rara da doença, com localização extracutânea.

\section{P0243 Cromoblastomicose - Tratamento com itraconazol sistêmico associado a anfotericina B intralesional}

\author{
AUTORES: Rossetto AL, Mora JM, Cruz RCB, Pereira EF, Cabral Filho PA. \\ INSTITUIÇÃO: Univ. do Vale do Itajaí (UNIVALI) e Hosp. Maternidade Marieta Konder Bornhausen - Itajaí, SC.
}

INTRODução: A Cromomicose é uma micose profunda, crônica, progressiva da pele e do subcutâneo, causada por fungos demáceos, sendo Fonsecaea pedrosoi o agente mais freqüente em nosso meio. Acomete principalmente os trabal hadores rurais do sexo masculino e geralmente com localização unilateral dos membros inferiores. As dificuldades financeiras dos pacientes em dispor da medicação, de modo geral, retardam, às vezes por anos, a procura pelo tratamento, que fazem irregularmente, tornando-se refratários às medicações prescritas. Em virtude desses fatos, são buscadas alternativas terapêuticas, inclusive as associações medicamentosas. 
Relato do Caso: Paciente de 69 anos, masculino, serviços gerais em madeireira, divorciado, natural de Itapema, reside em Camboriú, SC, há dois anos foi mordido por cachorro em antebraço direito, resultando em escoriações superficiais, sem tratamento, contato constante com serragem ao aplainar tábuas, evoluindo para lesão verrucosa. Exame clínico: placa verrucosa em região dorsal do antebraço direito, medindo cerca de $4 \times 6 \mathrm{~cm}$ de diâmetro, coloração acastanhada, bordos infiltrados e lesões vegetantes no centro da lesão tipo corno cutâneo. Exames complementares: bioquímica do sangue normal; anti-HIV 1 e 2, VDRL quantitativo, FTA-Abs IgG e IgM, Hbs-AG: não reagentes; Rx tórax: sem particularidades; exame anatomopatológico: epiderme apresentando hiperceratose com acantose. $\mathrm{Na}$ derme superficial denso infiltrado inflamatório granulomatoso com mononucleares, entre os quais linfócitos e histiócitos, células gigantes do tipo corpo estranho, neutrófilos e eosinófilos. Presença de grupos de estruturas parasitárias arredondadas de cor marrom no interstício ou dentro de células gigantes. Diagnóstico: cromoblastomicose. Exame micológico direto: presença de corpúsculos fumagóides. Cultura em meio Sabourarud na micromorfologia foi identificado o fungo Fonsecaea pedrosoi. Tratamento: Itraconazol 200 mg/dia VO, Anfotericina B 25 $\mathrm{mg} / \mathrm{semanal}$ intralesional.

Discussão: 0 tratamento da cromoblastomicose representa muitas vezes desafio para a prática dermatológica devido à freqüência de recidivas, dificuldade de adesão dos pacientes ao tratamento prolongado e paraefeitos dos antifúngicos. 0 tratamento com Itraconazol sistêmico, associado a Anfotericina B intralesional, foi utilizado devido à localização e extensão da lesão (dificultando a remoção cirúrgica completa da lesão) e devido aos discretos efeitos colaterais, com exceção da dor local, da anfoterecina B intralesional. Paciente apresentou boa resposta clínica, com resolução das lesões em 16 semanas de tratamento. 0 paciente encontra-se em acompanhamento ambulatorial.

Motivo DA APRESENTAÇÃo: Localização da lesão em membro superior e boa resposta terapêutica.

\title{
P0244 Tinea capitis em adulto por Trichophyton violaceum
}

\author{
Autores: $\quad$ Rossetto AL, Pereira EF, Weschenfelder GP, Gauze GE, Benvenuti, F. \\ INSTITUIÇÃo: Universidade do Vale do Itajaí - UNIVALI, Itajaí, SC
}

INTRODuÇÃo: A Tinea capitis é muito contagiosa e tem caráter epidêmico. São classificadas em microspórica, tricofítica e favosa. A tricofítica é causada freqüentemente pelos fungos Trichopyton tonsurans e Trichophyton violaceum e acomete, predominantemente, crianças do sexo masculino entre 3 e 14 anos e, em adultos, acomete mais as mulheres. 0 T. violaceum é um fungo antropofílico causador de infecções inflamatórias e infecções não-inflamatórias crônicas, na pele, nas unhas, na barba e couro cabeludo (tipo endotrix). É encontrado mais freqüentemente na Ásia, Europa, África, tornando-se raro no Brasil desde a década de 30. Sua clínica caracteriza-se pela presença de "black dots" nos locais de queda de cabelo, que são folículos pilosos obstruídos. Pode manifestar-se com descamação difusa com mínima perda de cabelo e inflamação.

Relato do Caso: Paciente de 65 anos, branca, natural e residente em Balneário Camboriú, SC, com queixa de queda e áreas com falhas de cabelos há 6 meses. Em uso de dipropionato de betametasona com ácido salicílico em solução capilar sem melhora e prurido eventual nas áreas afetadas. Negou outras doenças prévias, familiares com mesma sintomatologia e em uso de outras medicações. Ao exame físico presença de três placas de alopecia com pontos negros na base dos fios ("black dots") com reação inflamatória moderada, localizadas nas regiões frontal, occipital e próximo ao vértice do crânio. No exame com a lâmpada de Wood a fluorescência foi negativa. No exame micológico direto foi evidenciada a presença de pseudo-hifas e micélios. Na cultura em meio de Sabouraud a micromorfologia foi do fungo T. violaceum. Foi instituído o tratamento com terbinafina VO $250 \mathrm{mg} / \mathrm{d}$, oxiconazol em solução tópica 1x/d e shampoo de cetoconazol a $2 \% 1 x / d$ com duração de 56 dias. Como resultados, houve regressão completa do quadro e crescimento de vários fios de cabelos em 60 dias.

Discussão: Trata-se de uma paciente feminina, idosa, que apresentou quadro de alopecia compatível com a clínica do T. violaceum, sendo confirmado mo exame micológico. Apresentou melhora com o uso dos antifúngicos: terbinafina (sistêmico) e cetoconazol (tópico). Conforme trabalhos publicados, o T. violaceum, não acomete tanto os países da América Latina, ocorrendo em maior escala nos países da Europa, África e Ásia. Além disso, a paciente pertence à faixa etária não predominante da doença.

Motivo DA APRESENTAÇ̃̃o: Faixa etária incomum e raridade de infecções por T. violaceum no Brasil. 


\title{
P0245 Síndrome poliglandular auto-imune tipo I e Tinea corporis disseminada por Trichophyton rubrum
}

\author{
Autores: $\quad$ Melo BLA, Moura AKA, Criado PR, Martins JEC, Vasconcelos DM. \\ Instıтuıção: Hospital das Clínicas da Faculdade de Medicina da Universidade de São Paulo - São Paulo, SP.
}

INTRODUÇÃo: A síndrome poliglandular auto-imune tipo I é uma doença autossômica recessiva rara que freqüentemente associa-se a candidíase mucocutânea. 0 caso a ser relatado apresenta, além de candidose, tinea corporis disseminada por Trichophyton rubrum.

RéATO Do CASO: Paciente de 15 anos, sexo feminino, parda, há 10 anos apresentando placas eritemato-descamativas com limites nítidos pelo corpo, poupando apenas membros superiores. A paciente tem diagnóstico prévio de síndrome poliglandular auto-imune tipo I, fazendo parte do quadro: candidíase mucocutânea, hipotiroidismo, retardo puberal e diabetes mellitus tipo I. Também apresenta dislipidemia e hepatite C. Foi solicitado exame micológico direto das lesões eritemato-descamativas que evidenciou hifas hialinas septadas. I midazólicos foram prescritos, mas, como a paciente não obteve melhora clínica, foram realizadas biópsias e cultura com antifungigrama. $\mathrm{O}$ anatomopatológico com Grocott demonstrou presença de hifas filamentosas hialinas e a cultura foi consistente com Trichophyton rubum, sensível à griseofulvina, tendo sido iniciado o uso desta medicação.

Discussão: A síndrome poliglandular auto-imune tipo I é uma doença autossômica recessiva rara associada a mutações no gene regulador da auto-imunidade, havendo produção de auto-anticorpos direcionados a tecidos específicos, causando destruição destes, principalmente das glândulas endócrinas. As doenças mais associadas à síndrome são: candidíase mucocutânea, doença de Addison, hipoparatiroidismo, retardo puberal, hipotiroidismo e diabetes mellitus tipo I. A candidíase mucocutânea é relacionada a uma imunodeficiência específica contra Candida spp. No caso relatado, além da candidíase mucocutânea, a paciente apresenta tinea corporis disseminada de longa data e de difícil tratamento, podendo representar um outro tipo de imunodeficiência específica ao Trichophyton sp. Em revisão da literatura não foram encontrados relatos desta associação.

Motivo da APRESENTAÇ̃̃o: O relato do caso se justifica pela raridade desta associação, não sendo encontrado relato semelhante na literatura.

\section{P0246 Dermatofitose na face de difícil diagnóstico}

\author{
AUTORES: \\ INSTITUIÇÃO: \\ Lima DQSL, Mattos APIG, Fialho MB, Gripp AC. \\ Universidade do Estado do Rio de Janeiro, RJ
}

INTRODução: A dermatofitose é a infecção fúngica mais comum do homem, de distribuição universal, com maior prevalência nas zonas tropicais e subtropicais. Descreveremos um caso de difícil diagnóstco pelo quadro clínico exuberante.

ReLato do Caso: P.L.J.L., masculino, 18 anos, branco, solteiro, lavrador, nascido e residente em Teresópolis, RJ. Há 3 meses iniciou quadro com pápula eritematosa que em 1 mês progrediu para surgimento de novas lesões que confluíram, dando origem a placa eritemato-infiltrada com abundantes pústulas e bordas bem delimitadas na região malar, palpebral inferior e mentoniana esquerdas, com rarefação acentuada dos pêlos no local. Nega história de trauma na região. Procurou atendimento médico, tendo sido prescritas diversas aplicações de penicilina procaína, além de cefal exina, com discreta melhora da lesão, porém com piora posterior. Procurou nosso serviço, onde foi realizado exame micológico da secreção local, com exame direto evidenciando hifas hialinas, septadas, ramificadas e artroconídeos, cultura demostrou crescimento de Trichophyton mentagrophytes. Iniciada griseofulvina $500 \mathrm{mg} /$ dia por 21 dias e cliclopiroxolamina tópica com melhora da lesão. Evoluiu com formação de abcessos comunicantes na região malar, com exame micológico negativo do material drenado. Instituída drenagem dos abscessos com cefalexina $2 \mathrm{~g} /$ dia oral por 10 dias com melhora do quadro.

Discussão: T. mentagrophytes é um fungo zoofílico que por isso provoca no homem um quadro inflamatório mais intenso. A lesão inicial descrita pelo paciente foi primariamente na face, se estendeu e houve formação de pústulas e rarefação dos pêlos no local, logo trata-se de uma dermatofitose que se estendeu aos folículos com destruição destes e formação de pústulas, o que levou à confusão no diagnóstico. 0 paciente apresentou excelente resposta ao tratamento anti-fúngico.

Motivo DA APRESENTAÇÃo: Diagnóstico difícil, com avaliação por vários dermatologistas sem conclusão final, pois tratava-se de uma dermatofitose na face com invasão do folículo e formação de pústulas. 


\title{
P0247 Efeito da glucana em um caso de cromoblastomicose refratário a antifúngico
}

\author{
Autores: $\quad$ Azevedo CMPS, Leda YA, Oliveira TKM, Barbosa A, Branco DAC. \\ INSTITUIÇÃo: UFMA - LIDER - São Luis, MA
}

\begin{abstract}
INTRODuçÃo: A cromoblastomicose é uma infecção fúngica da pele e tecido celular subcutâneo, produzida por fungos dematiáceos. Apesar de ser relatada no Brasil desde 1920, a terapêutica da micose representa até hoje um grande desafio, principalmente nos casos moderados ou graves.

Relato de Caso: J.R.C.B., 50 anos, casado, branco, nascido em Santana (Morros), onde reside, lavrador e analfabeto. QP: lesões descamativas no tronco há 27 anos. HDA: o paciente refere que há 27 anos notou aparecimento de lesão nodular em face lateral direita do tronco, inicialmente única, pruriginosa, que evoluiu, aumentando em número e transformando-se em placas infiltrativas, descamativas e hiperemiadas, atingindo todas faces do tórax e porção superior do abdômen, em 8 anos de doença. Há 6 anos iniciou 0 aparecimento de lesão semelhante no nariz, que evoluiu atingindo as regiões malares, com forma de asa de borboleta. Procurou ajuda médica em 1997, com lesões disseminadas em tronco e face, sendo diagnosticado cromoblastomicose, causada por F. pedrosoi. O tratamento foi iniciado com Itraconazol, na dose de $200 \mathrm{mg}$ ao dia, subseqüentemente, $400 \mathrm{mg}$ ao dia, não se observando melhora clínica. Em 2000, com as lesões em franca disseminação, associou-se Terbinafina, sem resposta adequada. Assim, em dezembro de 2003, quando já apresentava destruição parcial do nariz e com lesões disseminadas em todo o tronco, iniciou-se o uso de glucana ( $\beta$-1-3- poliglicose do S. cerevisae), associado ao Itraconazol, na dose de 2,5 mg a $5 \mathrm{mg}$, apresentando em um mês os primeiros sinais de paralização da doença e redução lenta das lesões.

Dıscussão: 0 estudo imunológico mostrou antes do tratamento com glucana uma inibição antígeno específica da proliferação de linfócitos coletados a partir do sangue periférico. Em relação ao padrão de citocinas, observou-se a produção preferencial de IL-10 e TNF- $\alpha$. Não foi possível detectar IFN- $\gamma$. Entretanto, após tratamento com glucana, observou-se um aumento significativo da linfoproliferação de células do paciente na presença de antígenos de F. pedrosoi. $O$ padrão de citocinas também foi alterado, mostrando uma diminuição da produção de IL-10 e um aumento significativo de IFN- $\gamma$ e TNF- $\alpha$.

Motivo dA APRESENTAÇÃo: A cromoblastomicose é uma patologia que vem chamando cada vez mais atenção da comunidade científica. A busca de uma terapêutica eficaz em casos refratários ao tratamento antifúngico conservador é de extrema relevância. Portanto, a associação de glucana e itraconazol pode vir a ser um método terapêutico benéfico em considerável quantidade de pacientes portadores de cromoblastomicose.
\end{abstract}

\section{DEPARTAMENTO DE ONCOLOGIA CUTÂNEA}

\section{P0248 Lúpus erosivo palmoplantar e carcinoma espinocelular}

\author{
AUTORES: \\ Macedo DM, Costa CS, Vasconcellos MRA, Ferraz LB, Almeida FA. \\ INSTITUIÇÃO: \\ Universidade Federal de São Paulo - Escola Paulista de Medicina - São Paulo, SP.
}

INTRODuÇÃO: O lúpus eritematoso discóide (LED) pode acometer a superfície palmoplantar, resultando em úlceras dolorosas e debilitantes. Essas lesões geralmente são refratárias a diversos tratamentos, incluindo corticóides, antimaláricos, dapsona e azatioprina. Além de dolorosas, e de impedirem a deambulação, há um risco aumentado de carcinoma espinocelular (CEC) nestas lesões, principalmente em negros.

Relato de CASO: Paciente de 48 anos, sexo feminino, negra, portadora de lúpus há 15 anos com ulcerações recorrentes em palmas e solas, relata úlcera dolorosa na planta do pé esquerdo há 10 meses com aumento progressivo do tamanho e secreção amarelada fétida. Nega febre ou emagrecimento. Durante o acompanhamento ambulatorial, as úlceras foram refratárias ao uso de corticóides, hidroxicloroquina, metotrexato, azatioprina e, embora responsivas à talidomida, a droga foi suspensa por dor tipo neuropática nos membros inferiores após 9 anos de uso. As lesões foram biopsiadas seqüencialmente sem encontro de neoplasia. É tabagista. 0 exame dermatológico mostrou úlcera profunda de formato irregular estendendo-se da região do cavo até calcanhar do pé esquerdo, apresentando bordas infiltradas, halo eritêmato-acastanhado, fundo vegetante e secreção purulenta amarelada. A outra planta e as palmas apresentavam lesões atrófico cicatriciais. A lesão biopsiada confirmou 